\title{
Highlights of the 3rd conference of the Romanian Association of Immuno-Dermatology and the 37th conference of the Romanian Society of Immunology held in Bucharest between September 19 and 22, 2019
}

\author{
DANIEL BODA $^{1,2}$ and CONSTANTIN CARUNTU ${ }^{1,2}$ \\ ${ }^{1}$ Dermatology Research Laboratory, 'Carol Davila' University of Medicine and Pharmacy, 050474 Bucharest; \\ ${ }^{2}$ Department of Dermatology, 'Prof. N. Paulescu' National Institute of Diabetes, \\ Nutrition and Metabolic Diseases, 011233 Bucharest, Romania
}

Received November 4, 2019; Accepted November 7, 2019

DOI: $10.3892 /$ etm.2019.8174

The combined 3rd conference of the Romanian Association of Immuno-dermatology and 37th conference of the Romanian Society of Immunology was held in Bucharest between September 19 and 22, 2019. The presentations were included in a call for a special issue on immunological processes involved in skin diseases and in cancer. The following articles are presented in this special issue:

In the article 'Reinforcing involvement of NK cells in psoriasiform dermatitis animal model', Surcel et al (1) used the imiquimod-based mouse model of psoriasiform dermatitis and NK cell complex phenotype patterns from peripheral blood and spleen were investigated. The maturation markers (CD11b, CD43, CD27, KLRG1) were found increased in NK cells, in periphery and spleen, while $\mathrm{CD} 49 \mathrm{~b}^{+} \mathrm{NK} 1.1^{+}$was found significantly lower, and these changes were associated with the severity of the disease.

Porumb-Andrese et al (2) examined the association between personality type, an affective distress profile and the quality of life in patients with psoriasis versus that of patients with cardiovascular disease. The authors demonstrated that it is necessary to include items evaluating the patients' affective profiles and personality in the assessment protocols of these diseases.

Grajdeanu et al (3) summarized in their review article entitled 'Imaging techniques in the diagnosis and monitoring of psoriasis' the current developments in the field of psoriasis

Correspondence to: Dr Daniel Boda, Dermatology Research Laboratory, 'Carol Davila' University of Medicine and Pharmacy, 8 Eroii Sanitari Avenue, 050474 Bucharest, Romania

E-mail: daniel.boda@yahoo.com

Key words: psoriasis, dermatitis, imuno-dermatology, skin non-invasive imaging techniques, such as dermoscopy, conventional ultrasound and high frequency ultrasonography (HFUS), videocapillaroscopy (VC), reflectance confocal microscopy (RCM), optical microangiography (OMAG), laser Doppler imaging (LDI), multiphoton tomography (MPT) or optical coherence tomography (OCT).

In the study 'High-frequency ultrasonography of psoriatic skin: A non-invasive technique in the evaluation of the entire skin of patients with psoriasis: A pilot study', S,omlea et al (4) intended to evaluate lesional and non-lesional skin from psoriatic patients with the use of high-frequency ultrasonography (HFUSG), focusing on the immune-induced inflammation and skin thickness. The authors considered that skin HFUSG should be used as a quantitative method in the clinical evaluation of the patients with psoriasis and may aid as an objective means of assessing inflammation in lesional skin.

Mocanu et al (5) examined the reasons for non-adherence to anti-TNF $\alpha$ agents (Infliximab, Adalimumab and Etanercept) used for the treatment of 84 cases with moderate-severe psoriasis, proving that the highest adherence rate was recorded with Adalimumab (80.8\%), followed by Infliximab (76.5\%) and Etanercept (70.9\%).

In the study by Stanca et al (6), the authors aimed to identify and describe anatomical and functional changes in the short-term (1-3 months) and medium-term (6-12 months) following intravitreal injections of bevacizumab (Avastin, Genentech) in patients with choroidal neovascularization (CNV) in the context of an exudative form of age-related macular degeneration (AMD). The authors proved that the use of bevacizumab in the treatment of subretinal neovascular membranes was effective and safe in the short- and medium-term, with the improvement of BCVA and the reduction of macular edema in a significant number of cases.

Boia et al (7) aimed to evaluate and compare the clinical and microbiological effects of two different regimens of amoxicillin (AMX) and metronidazole (MTZ), combined 
with non-surgical periodontal therapy in patients with chronic periodontitis (CP). They also aimed to identify antibiotic-resistant bacteria and changes in oxidative stress (OS).

Marcu et al (8) searched the existing data regarding minimally invasive retroperitoneal tumor biopsy using the PubMed database, in order to evaluate the role of this procedure in establishing a correct diagnosis, as well as to identify the risks of tumor cell seeding and local recurrence following needle biopsy.

In the review article entitled 'Therapeutic options in patients with biochemical recurrence after radical prostatectomy', Bratu et al (9) systematically screened the recent literature regarding the management of biochemical recurrence and compared clinical experience in literature studies. The main primary treatment of this type of cancer is represented by radical prostatectomy (RP), which yields marked oncologic results.

In the review article entitled 'Venous thromboembolism in cancer patients: Still looking for answers', Iorga et al (10) aimed to assess the efficacy and safety of venous thromboembolism prophylaxis in cancer patients, which is associated with a greater risk of developing venous thromboembolism recurrence and major hemorrhagic events.

Ștefanache et al (11) have demonstrated in previous studies that that the peptides, defensin and cathelicidin LL37, exert cytostatic effects on the following human tumor cell lines: HT29 (colorectal adenocarcinoma) and A549 (alveolar carcinoma). In their original article, entitled 'Modulation of the activity of certain genes involved in tumor cell metabolism in the presence of the cytotoxic peptides defensin and cathelicidin LL37', they assessed the gene expression of the AKT, HIF-1 $\alpha$, XBP, NRF2, PERK, CHOP, BCL2, IRE1 $\alpha$ and PI3K molecular targets involved in the survival, growth, proliferation and apoptosis pathways of tumor cells in the presence or absence of the peptides examined.

Bostan et al (12) in their original article entitled 'Cisplatin effect on head and neck squamous cell carcinoma cells is modulated by ERK1/2 protein kinases', examined the mechanisms through which curcumin (CRM) used as an adjuvant supports the apoptotic process induced by a single chemical agent treatment (cisplatin-CisPT) on two head and neck squamous cell carcinoma cell lines (FaDu and PE/CA-PJ49) and the involvement of ERK1/2 and/or p53 activation in this process. They proved that the use of CRM as adjuvant increased the efficiency of chemotherapy by modulating cellular activation processes of ERK1/2 signaling pathways.

Fekete et al (13) reported, in a case presentation, the association between paraneoplastic pityriasis rubra pilaris and prostate carcinoma, concluding that PRP can be considered a paraneoplastic syndrome; therefore, tumor screening is mandatory in cases presenting this disease.

In the review article entitled 'Pemphigus vulgaris - approach and management', Popescu et al (14) focused on the pathogenesis and treatment of this autoimmune disease triggered by $\operatorname{IgG}$ autoantibodies directed against desmogleins 1 and 3 , which are part of the cadherin family of cell-cell adhesion molecules.

Ancuceanu et al (15) aimed to investigate the frequency of rash as an adverse drug reaction, based on the information provided by SmPCs of 1,048 single active substances (international non-proprietary names) authorized in the United Kingdom.

Liu et al (16) aimed to investigate the expression of vascular adhesion protein-1 (VAP-1) in patients with systemic lupus erythematosus (SLE) associated with conjunctivitis and to examine the association between VAP-1 and other proteins in the onset of the disease in their study entitled 'Exploration of vascular adhesion protein-1 expression in patients with conjunctivitis associated systemic lupus erythematosus using 2D-DIGE'

In their article, entitled 'Clinical impact of omalizumab in refractory chronic urticaria: One centre experience', Deleanu et al (17) bring forth updates in chronic urticaria approach, with a focus on our experience with anti-IgE therapy in different forms of chronic urticaria treated at the Allergy Department of the Professor Doctor Octavian Fodor Regional Institute of Gastroenterology and Hepatology, Cluj-Napoca, Romania.

Stanca et al (18) undertook a retrospective study focused on toxic coma in children aiming to identify rapidly the etiology of toxic coma in children, to appreciate the severity of the coma, to detect elements of gravity based on associated clinical signs and symptoms and to evaluate the initial treatment.

Deleanu et al (19) in the article entitled 'Knowledge influences attitudes toward vaccination in Romania' predicted that better knowledge regarding vaccines, their efficacy and safety would help build the health provider's confidence in recommending vaccination and thus increased coverage rates.

Petcu et al (20), in their original article entitled 'Upper gastrointestinal involvement in systemic sclerosis: Findings in a real life setting', aimed to investigate the endoscopic and histopathological gastroesophageal findings in patients with SSc. The results of this study suggest that upper gastrointestinal endoscopy should be performed during the early stage of the disease and then periodically in patients diagnosed with SSc, even in the absence of typical symptoms.

Păcurar et al (21), in their article entitled 'Autoimmune phenomena in treated and naive pediatric patients with chronic viral hepatitis' demonstrated that the occurrence of autoimmune phenomena was delayed when the patient was treated with interferon-based regimens when compared to naive patients.

Ali et al (22) in their article entitled 'A rapid desensitisation protocol in a case of drotaverine induced serum sickness-like reaction in a pregnant woman: A case report' reported the first case report of desensitisation to drotaverine, previous involved in a serum sickness-like reaction.

Costescu et al (23) in their article entitled 'Antidepressant effect of the interaction of fluoxetine with granisetron' demonstrated that low doses of granisetron with fluoxetine may produce a significant antidepressant effect, suggesting a potentiation between these two drugs used in sub-effective antidepressant doses.

The Editors would like to take this opportunity and thank all the authors for their valuable contributions, as well as the reviewers, whose important suggestions were of paramount importance. 


\section{References}

1. Surcel M, Munteanu AN, Huică RI, Isvoranu G, Pîrvu IR, Constantin C, Bratu O, Căruntu C, Zaharescu I, Sima L, et al: Reinforcing involvement of NK cells in psoriasiform dermatitis animal model. Exp Ther Med 18: 4956-4966, 2019.

2. Porumb-Andrese E, Vâtă D, Postolică R, Stătescu L, Stătescu C, Grăjdeanu AI, Pătrașcu AI, Popescu IA and Solovastru LG Association between personality type, affective distress profile and quality of life in patients with psoriasis vs. patients with cardiovascular disease. Exp Ther Med 18: 4967-4973, 2019.

3. Grajdeanu IA,Statescu L, Vata D, Popescu IA,Porumb-AndreseE, Patrascu AI, Taranu T, Crisan M and Solovastru LG: Imaging techniques in the diagnosis and monitoring of psoriasis (Review). Exp Ther Med 18: 4974-4980, 2019.

4. Somlea MC, Boca AN, Pop AD, Ilies RF, Vesa SC, Buzoianu AD and Tătaru A: High-frequency ultrasonography of psoriatic skin: A non-invasive technique in the evaluation of the entire skin of patients with psoriasis: A pilot study. Exp Ther Med 18: 4981-4986, 2019.

5. Mocanu M, Toader MP, Rezus E and Taranu T: Aspects concerning patient adherence to anti $\mathrm{TNF} \alpha$ therapy in psoriasis: A decade of clinical experience. Exp Ther Med 18: 4987-4992, 2019.

6. Stanca HT, Stanca S, Tabacaru B, Boruga M and Balta F: Bevacizumab in Wet AMD treatment: A tribute to the thirteen years of experience from the beginning of the anti VEGF era in Romania. Exp Ther Med 18: 4993-5000, 2019.

7. Boia S, Boariu M, Baderca F, Rusu D, Muntean D, Horhat F, Boia ER, Borza C, Anghel A and Stratul ŞI: Clinical, microbiological and oxidative stress evaluation of periodontitis patients treated with two regimens of systemic antibiotics, adjunctive to non-surgical therapy: A placebo-controlled randomized clinical trial. Exp Ther Med 18: 5001-5015, 2019.

8. Marcu RD, Diaconu CC, Constantin T, Socea B, Ionita Radu F, Mischianu DL and Bratu OG: Minimally invasive biopsy in retroperitoneal tumors (Review). Exp Ther Med 18: 5016-5020, 2019.

9. Bratu OG, Diaconu CC, Mischianu DL, Constantin T, Stanescu AM, Bungau SG, Ionita Radu F and Marcu RD: Therapeutic options in patients with biochemical recurrence after radical prostatectomy (Review). Exp Ther Med 18: 5021-5025, 2019.

10. Iorga RA, Bratu OG, Marcu RD, Constantin T, Mischianu DL, Socea B, Gaman MA and Diaconu CC: Venous thromboembolism in cancer patients: Still looking for answers (Review). Exp Ther Med 18: 5026-5032, 2019.

11. Stefanache T, Forna N, Bădescu M, Jitaru D, Dragos ML, Rezuș C, Diaconescu BM, Bădulescu O, Rezus E, Ciocoiu M, et 'al: Modulation of the activity of certain genes involved in tumor cell metabolism in the presence of the cytotoxic peptides defensin and cathelicidin LL37. Exp Ther Med 18: 5033-5040, 2019.
12. Bostan M, Petrică Matei GG, Ion G, Radu N, Mihăilă M, Hainăroşie R, Braşoveanu LI, Roman V, Constantin C and Neagu MT: Cisplatin effect on head and neck squamous cell carcinoma cells is modulated by ERK1/2 protein kinases. Exp Ther Med 18: 5041-5051, 2019.

13. Fekete GL, Boda D, Căruntu C and Fekete L: Paraneoplastic pityriasis rubra pilaris in association with prostate carcinoma: A case report and literature review. Exp Ther Med 18: 5052-5055, 2019.

14. Popescu IA, Statescu L, Vata D, Porumb-Andrese E, Patrascu AI, Grajdeanu IA and Solovastru LG: Pemphigus vulgaris - approach and management (Review). Exp Ther Med 18: 5056-5060, 2019.

15. Ancuceanu R, Dinu M, Furtunescu F and Boda D: An inventory of medicinal products causing skin rash: Clinical and regulatory lessons. Exp Ther Med 18: 5061-5071, 2019.

16. Liu H, Zhang J, Zhou P, Sun H, Katsarou M and Drakoulis N: Exploration of vascular adhesion protein-1 expression in patients with conjunctivitis associated systemic lupus erythematosus using 2D-DIGE. Exp Ther Med 18: 5072-5077, 2019.

17. Deleanu D, Nedelea I, Petricau C, Leru P, Dumitrascu D and Muntean A: Clinical impact of omalizumab in refractory chronic urticaria: One centre experience. Exp Ther Med 18: 5078-5081, 2019.

18. Stanca S, Ulmeanu CE, Stanca HT and Iovanescu G: Clinical features in toxic coma in children. Exp Ther Med 18: 5082-5087, 2019.

19. Deleanu D, Petricau C, Leru P, Chiorean I, Muntean A, Dumitrascu D and Nedelea I: Knowledge influences attitudes toward vaccination in Romania. Exp Ther Med 18: 5088-5094, 2019.

20. Petcu A, Ghib LJ, Grad SM, Popovici C, Rogojan L, Rednic NV and Rednic S: Upper gastrointestinal involvement in systemic sclerosis: Findings in a real life setting. Exp Ther Med 18: 5095-5100, 2019.

21. Păcurar D, Dijmărescu I, Dijmărescu A, Pavelescu M, Andronie M and Becheanu C: Autoimmune phenomena in treated and naive pediatric patients with chronic viral hepatitis. Exp Ther Med 18: 5101-5104, 2019.

22. Ali S, Corcea SL, Cristian RM and Bumbacea RS: A rapid desensitisation protocol in a case of drotaverine induced serum sickness-like reaction in a pregnant woman: A case report. Exp Ther Med 18: 5105-5107, 2019.

23. Costescu M, Paunescu H, Coman OA, Coman L and Fulga I: Antidepressant effect of the interaction of fluoxetine with granisetron. Exp Ther Med 18: 5108-5111, 2019.

This work is licensed under a Creative Commons Attribution-NonCommercial-NoDerivatives 4.0 International (CC BY-NC-ND 4.0) License. 